\title{
Artificial Intelligence and Its Reportage in Select Nigerian Newspapers: A Content Analysis
}

\author{
GUANAH Seigha Jammy \\ Department of Mass Communication, Chukwuemeka Odumegwu Ojukwu University \\ Igbariam Campus - Anambra State, Nigeria. \\ jammyguanah@yahoo.com \\ OBI Ijeoma \\ Department of Mass Communication, Chukwuemeka Odumegwu Ojukwu University \\ Igbariam Campus - Anambra State, Nigeria. \\ obiijeoma14@yahoo.com \\ GINIKACHUKWU Alpha Chukwuemeka \\ Department of Mass Communication, Chukwuemeka Odumegwu Ojukwu University \\ Igbariam Campus - Anambra State, Nigeria. \\ grace4alfa@gmail.com
}

DOI: http://doi.org/10.36892/ijlls.v2i2.298

Abstract
$\begin{aligned} & \text { Received: } \\ & \text { 01/05/2020 }\end{aligned}$
The emergence of Artificial Intelligence (AI) is gradually having effects in most
facets of the society; and no area tends to be exempted from this AI bug. This
research explored the discourses of the place of the media, especially newspapers,
as the watchdogs of the society in this unfolding scenario. It was expected that the
media should be at the forefront in letting citizens know its implications. The study
set out to determine the volume of coverage given to news about Artificial
Keywords:
Intelligence (AI) by The Punch, The Guardian, and Vanguard newspapers; to
Artificial Intelligence;
identify the story types through which AI stories were reported by the newspapers,
Media; Newspapers;
and to examine if the newspapers gave prominence to AI stories. The study was
Reportage
anchored on the Agenda Setting Theory while Content Analysis was adopted as the
research method for obtaining data from a population of 1,095 made up of the
newspapers editions from January to December 2019, and a sample size of 285
derived through the use of the Creative Research System Calculator. The study
revealed that only 64 AI stories appeared in the selected newspapers throughout
2019. It also discovered that most of the stories were in photograph form, and that
prominence was not given to AI stories by the newspapers. It was therefore
concluded that since automation may be the future, newspapers must start to
intensify in educating the public about AI through their coverage. The study
recommended among other things that newspapers should give prominence to AI
stories. Also, they should report AI stories with all story types, and place such
stories in all the prime sections of the newspapers.

INTRODUCTION

The "invasion" of the human space by Artificial Intelligence (AI) is being felt in all areas of human life. Handley (2018) quotes Ali Shafti as defining AI "as a non-human device or algorithm being able to do behaviours and actions that are possible only for a person of human intelligence, or maybe not even possible for humans, so above human intelligence" (p.2). 
According to Ladi Ojora, "True Artificial Intelligence is the empowerment of computer systems with the ability to independently learn and make decisions exclusively of the programmer or system that created it" (in Ndiomewese, 2017, p.2).

Agreeing that there is no internationally agreed definition of AI, Vinuesa, Azizpour and Nerini (2020) define AI as any software technology with at least one of the following capabilities: perception-including audio, visual, textual, and tactile (e.g., face recognition), decision-making (e.g., medical diagnosis systems), prediction (e.g., weather forecast), automatic knowledge extraction and pattern recognition from data (e.g., discovery of fake news circles in social media), interactive communication (e.g., social robots or chat bots), and logical reasoning (e.g., theory development from premises). They submit that it encompasses a large variety of subfields, including machine learning. Phillips (2018) quotes Joris Gielen, an AI and Software Engineer at Twipe, as saying that "Machine learning uses algorithms that gradually improve on a task without explicitly being told how, i.e. they 'learn' from data" (p.2).

Technology has not only transformed our awareness of what is happening around the world, but technologies such as artificial intelligence and machine learning are also changing the way we live our lives. Abdullah (2018) predicts that in the next eight years, most business models would disappear, and most industries would run bankrupt because AI has already, and would further impact professions like law where IBM Watson give "legal advice within seconds, with $90 \%$ accuracy compared with $70 \%$ accuracy when done by humans" (p.1). In the field of medicine/health too, AI (Watson) helps nurses diagnose cancer, four times more accurate than human nurses. Also, Companies have built a medical device called the "Tricorder", that works with one's phone, taking one`s retina scan, blood sample, and when one breathes into it, it analyses 54 biomarkers that will identify nearly any disease. These are some of the feats AI performs.

Abdullah (2018) also asserts that, by 2022 most people will not need to own cars anymore because they can easily call a car with their phones, and it will show up and drive them to their destinations. This autonomous driving will reduce accidents drastically and shrink insurance companies' income. It will also have effects on real estate too because people can now live better further away, and cities will be less noisy because cars will be electric. The activities AI perform now, and will perform in the future made Kuziemski (2017) to declare that Artificial Intelligence do not only have the potential to make or break the world order, but that it will penetrate and permanently alter every industry in existence, and also change the boundaries and meaning of being human.

All these indicate that AI has the potential to cause significant disruptions to many hitherto known and established ways of doing things all over the world, including Nigeria. With the reality on ground, Nigeria and Nigerians will be affected by AI operations. If this is the case; how much has the Nigerian media done to inform and educate the citizens about it? It seems most Nigerians are still not well informed about AI. Ndiomewese (2017) expressed his shock when he asked a final year student of computer science of a Nigerian University what he knew about Artificial Intelligence, and he was clueless. He said others he questioned about their understanding of AI were fazed by the question.

As conversed by Azeez (2009), one of the major functions of the mass media is the provision of adequate information about ongoing or current events in the society as a way of serving the public. Illah, Ogwo and Asemah (2012) also agree that the mass media do not only perform the watchdog role in the society, they also serve as the eyes and ears of the public by providing information about the changes that take place in the society. The trio opine that it is the basic responsibility of the media to "survey the environment and report to the people in 
order to reduce uncertainties and increase the probability that the audience will react to conflicts and changes in a rational way" (p.15). They admit that the media in their surveillance activities scout round their environment so as to report news about development, danger, threats to public welfare, national stability and so on. It is the duty of newspapers to report about AI and the sweeping effects it will bring on Nigerians. The people need to be informed on how to apply themselves in the face of AI invasion that will surely affect their lifestyle. Just as Schlesinger, Murdock and Elliot (1983) put it, the public is in greater need of more extensive information during a current danger in order to reduce uncertainty about the danger. Newspapers are, therefore, under obligation to meet these information need of the public.

Having realised the inevitability of AI in the affairs of man, and recognising the vital role of newspapers in the society, this study investigated the level of reportage given to AI stories by The Punch, The Guardian, and Vanguard newspapers from January to December, 2019. sThe choice of print (newspaper) was made above other media of communication because it ranks ahead in content compared to the television which ranks ahead in breadth of perception; and the radio which ranks ahead in availability (Daramola, 2001). Newspaper is also far ahead of other medium of communication (ACE Project, 2019), and because of its more 'serious' profile than other forms of media (Walgrave \& Aelst; Walgrave, Soroka \& Nuytemans). These newspapers were selected due to their wide readership, and because they are among the top 10 national dailies in Nigeria (Nwabueze, 2018). January - December, 2019, a twelve-month period, was chosen for this study because it gave ample time to really determine if the newspapers gave enough coverage to AI stories. This study determined to enquire if newspapers in Nigeria are keeping readers abreast of the happenings in the AI world, taking into consideration the fact that it will alter most aspects of human lives.

\section{Statement of the Problem}

It is an unarguable fact that AI has come to stay, and it will have enormous impact on society now and in the nearest future. Most people may probably lose their jobs due to the suspicion that AI will cause unprecedented job displacements. People would have to be prepared for the world of AI which is fast approaching. However, there seems to be no assurance that the media, especially newspapers, who are the watchdogs of the society, are educating and enlightening the public about AI and its effects through their reportage and placements. This study therefore employed the research design of content analysis of reportage of $\mathrm{AI}$ in the three selected newspapers.

\section{Objectives of the Study}

The objectives were to:

i. To determine the volume of coverage given to news about Artificial Intelligence (AI) by the selected newspapers.

ii. To identify the story types in which AI stories were reported by the selected newspapers. iii. To examine if prominence was given to AI stories by the selected newspapers.

\section{Theoretical Consideration}

This study drew inspiration from the Agenda Setting Theory of the media. This theory was postulated by Maxwell McCombs and Donald Shaw (McCombs \& Shaw, 1972. Cohen (1963) explains the concept thus: The press is significantly more than a purveyor of information and opinion. It may not be successful much of the time in telling people what to think, but it is stunningly successful in telling its readers what to think about. And it follows from this that the world looks different to different people, depending not only on their 
personal interests, but also on the map that is drawn for them by writers, editors and publishers of the papers the read (Baran \& Davis, 1995, p.232).

However, Cohen`s work is traceable to studies made during the penny press by Walter Lippman. Lippmann stated in 1992 that the mass media act as the mediator between "the world outside and the pictures in our heads' (Griffin, 2003, p. 333). He felt that people did not deal directly with their environments as much as they responded to the "pictures" in their heads because it was too complex and too fleeting for direct and immediate understanding. Ordinary people were assumed to lack the ability to handle complexities and varieties, hence the elites who are assumed to possess the ability, do so on their behalf. Wright (1986) citing Maxwell McCombs and Donald Shaw, opines that:

In choosing and displaying news, editors, newsroom staff, and broadcasters play an important part in shaping political reality. Readers learn not only about a given issue, but how much importance to attach to that issue from the amount of information in a news story and its position. The mass media may well determine the importance - that is, the media may set the 'agenda' of the campaign (p. 153).

In other words, it is the issues of the society that the media focus on in their reportage that eventually become the topics of discussion by the people. Sometimes, the media go beyond just setting the agenda for the society, but also frame the news for the society to see things from a particular perspective, and prime some news stories by emphasising on them to create a particular effects for the society to align with. This theory is relevant to this study because it is the duty of the media to lead the way in the discussion on salient issues like the AIs that has the tendency to affect the lifestyles of citizens that the media are responsible to.

\section{The world of Artificial Intelligence}

The fact that AI is finding its way into every facet of human life is no longer news; in fact, Hall (2018) points out that the AI industry is expected to expand by a compound annual growth rate (CAGR) of 50\% from 2015-25, and that by 2025 it would have grown up to $\$ 127$ billion. Rooney (2019) asserts that the implementation of AI technology, including robots, is expected to add as much as $\$ 15.7$ trillion to the global economy by 2030 . The implication of this is that AI is bound to change the economic face of the whole world. For now it is developed countries that are investing so much into AI, and this might leave developing countries in a precarious position if they too do not start now to invest in AI technology.

At a rapid pace, AI is impacting almost all areas of human endeavours, and it is being utilised in various fields, be it manufacturing, entrepreneurship, warehousing, retail, business communication, haulage, entertainment, sales and marketing data, hotels, restaurants, agriculture, healthcare, and much more. According to Hendricks (2018), a study carried out by the Institute for the Integration of Latin America and the Caribbean (INTAL), indicates that by 2022, 62 per cent of organisations' information, data processing and information search and transmission tasks will be performed by machines compared to 46 per cent today.

Correspondingly, Marciano (2017) reports that in a landmark study, 20 top United State corporate lawyers with decades of experience in corporate law and contract review were pitted against an AI. Their task was to spot issues in five Non-Disclosure Agreements (NDAs), which are a contractual basis for most business deals. Marciano (2017) reports that the study, carried out with leading legal academics and experts, saw the LawGeex AI achieve an average 94\% accuracy rate, higher than the lawyers who achieved an average rate of $85 \%$. It took the lawyers an average of 92 minutes to complete the NDA issue spotting, compared to 26 seconds for the LawGeex AI. The longest time taken by a lawyer to complete the test was 156 minutes, and the 
shortest time was 51 minutes. The efficiency that $\mathrm{AI}$ is bringing along with it is enormous. The ease of transacting various businesses will not only be guaranteed by AI, but there will be a lot more things being achieved in less time. For instance, the judiciary will benefit greatly because there will be rapid discharge of court matters. The challenge African countries, especially Nigeria, will face in this case is catching up with the AI technology early.

Also, White and Pinsky (2018) opine that a time will come when people will be connected to a vast Internet of Things network that will feed unimaginable amounts of data into ever more advanced artificial intelligence tools, enabling people to create new and highly disruptive products and services that generate huge amounts of wealth. Abdullah (2018) says Facebook has a pattern recognition software that can recognize faces better than humans, and that in 2030, computers will become more intelligent than humans. An innovation like this is laudable, but it usurps people of their liberty and privacy because such technologies are deployed without the express permission of the people concerned.

Speaking to students of Bowen University, Iwo in Osun State, Nigeria, Technology Strategist, Olufemi Oyenuga gave the instance in the Agricultural sector in Scotland where they put sensors inside cows, and those sensors keep data back to a centralized system that processes data and tells them when the cows want to mate or produce milk. The data are said to be monitored every day by farmers. They get to know exactly when to go and milk the cow. Olufemi Oyenuga said further that AI is used in tomato cultivation in Spain where they put sensors in the soil to understand the soils texture and the composition of the soil, and "that automatically translates to the kind of tomato that comes out from that farm" (Umeh, 2019, p. 3). Meanwhile, AI is also performing feats in film making where potential AI-driven applications are taking over and are learning and thinking for themselves. They could function as script supervisors, take a first pass at film editing, create performances either for digital characters that resemble actual humans, or more fantastic CG creatures (Giardina, 2017).

Nigeria can leverage on the AIs that have to do with agriculture and the creative industry because these are areas that the country is known to be doing well in. Agriculture is important to the economic development of the country because it provides food and employment for a lot of persons. With AI deployed to Nigeria`s agricultural sector, there will be food security. Even without AI Nigeria`s creative industry raked into the nation's economy the sum of $\$ 104 \mathrm{~m}$ in 2019, from just film and music (Afolayan, 2020). What the country will benefit if AI is used in all aspects of the creative industry will be quite unimaginable.

Xiang (2019) has the founder of Infervision, Kuan Chen, on record as submitting that AI enhances diagnostic abilities that medical image reading on pulmonary nodules performed by a junior doctor assisted by AI has no statistical difference from that of a veteran doctor. Kuan Chen claims that AI is prominent in handling cases like strokes, diseases and auxiliary diagnosis. Emphasising that "AI can help level the healthcare resource imbalances between urban and rural areas, and between more developed and less developed regions" (Xiang, 2019, p. 2). Medical tourism is a bane on Nigeria`s economy, as millions of naira are spent by Nigerians who travel out of the country to seek medical attention overseas yearly. However, if the country`s hospitals are well equipped with modern AI medical technologies, medical tourism will be drastically reduced, if not stopped entirely. The situation whereby it will take days for results of simple medical examinations to be obtained will be a thing of the past with AI.

Thornton (2019) adds that OceanMind`s system currently tracks thousands of boats, with the capability of tracking millions, across the globe by gathering data from a wide range of sources, including collision-avoidance transponders aboard boats; radar images; satellite 
imagery; and cellphone signals. Analysing these enormous dataset is beyond the capability of any one person. OceanMind has developed machine-learning algorithms that predict the type of fishing behaviour based on vessel location, and flags suspicious and potentially illegal activity such as fishing too close to the shore. OceanMind's fisheries experts verify the alerts flagged by $\mathrm{AI}$ and coordinate closely with the relevant authorities, who can then decide whether to investigate further. OceanMind's AI will be very useful in Nigeria`s Maritime sector where a lot of sea piracy, kidnapping, and other crimes are going on. It can also be used to checkmate the activities of foreign fishing trawlers that ilgally stray into Nigeria`s territorial waters to fish. The Nigerian Maritime sector is a multi-million naira fund generator for the country, and the deployment of relevant AIs to boost the sector will not be out of place, as the country is bound to benefit from such deployments of AIs.

Talking about Facial recognition, Leprince-Ringuet (2019) declares: This new AI tool can spot when you are nervous or confused. Fujitsu Laboratories has developed a technology that is more accurate at tracking complex facial expressions such as awkward giggles, nervousness or confusion. In Japan, an AI software that can prevent crime by analyzing surveillance camera footage in order to detect suspicious behavior and prevent shoplifting before it actually happens has been developed. The software called VaakEye, which is credited with reducing shoplifting cases by 75\%, debuted in December 2018 when it picked up on previously undetected shoplifting activity at a convenience store in Yokohama. The suspect, an 80-year-old man, was apprehended a few days later after stealing a hat.

Nwabueze (2019a) cites IT Media as explaining that VaakEye is based on a complex algorithm that harnesses deep learning from more than 100,000 hours of surveillance footage, and analyses over 100 different factors, from a person`s face, clothes, movement, overall behavior, to macro-data like crime incidence in the area the shop is located in, or current weather conditions. VaakEye helps to prevent a crime from being committed in a shop by prompting shop staff to approach suspicious subjects after receiving an alert from the software and ask if they need some help. This is done to discourage suspected shoplifters from going ahead with their plans. There are plans to enhance the VaakEye`s functionality so that it could also be used to analyse the way consumers interact with various products, thus helping businesses better display their goods, and also in public spaces and train platforms to detect suspicious behavior and prevent suicide attempts. Surely, AI can help to nib crime in the bud. The consciousness that one's actions and movements are being monitored can serve as a deterrence to committing a crime. Apart from business premises and residential homes, if AIs like VaakEye are installed in troubled spots around the country, it will complement the jobs security agencies.

AI is also useful in weather forecast and switch to music with the provision of far more sophisticated digital aides instead of Siri and Alexa being used. Cann (2018) asserts that there is a new technology that is powered by AI that will mine the cloud and outline various arguments on topics that are important to everybody, without prior training. Nwabueze (2019b) names Mirror UK as saying that Kairinos, the founder of Fountech.ai, that specialises in the development of artificial intelligence solutions for businesses and organisations, and who has racked up more than 20 years of working with start-ups, affirms that AI could enable teachers to deliver tailored lessons that cater for the learning needs of each individual pupil- no matter their learning style. Kairinos claims that there is an AI device that can read facial expressions to determine whether a student (who could be nine or 90 years old) is reacting positively or negatively to different learning methods. Periodic flooding takes place in Nigeria due to heavy rain falls, and it has always been devastating because they leave in their trails destruction of 
lives and property. With the AI that can predict weather, dwellers of low plains that could be affected by flooding could be warned well ahead of time before heavy rains that could cause flooding comes. Also, the AIs that can be used in the education sector will boost the education system of the country, since they can aid all categories of leaners, no matter their ages or sexes.

According to Houser (2019), since October 2019, Swedish recruitment agency TNG has been using an AI robot head called Tengai to conduct test interviews in place of a human recruiter. Starting in May, the device will begin interviewing candidates for actual jobs with the goal of eliminating the biases human recruiters bring to the hiring process. AI equally plays a great role in the world of business where companies are using AI (machine learning) to make predictions based on data. Hughes (2017) explains that as a result of this, "we're seeing solutions such as Robotic Process Automation (RPA) and big data, driving efficiencies and boosting profits" (p. 2). Sherman (2018) affirms that companies across many industries already have robots in their workforce. He gave example of DHL that uses autonomous robots by Fetch Robotics to help fulfillment center and warehouse employees; Toyota, Google and Panasonic also use Fetch's mobile manipulator technology in research efforts. Sometimes the most competent people do not get employed after interviews because of the human factor. Such anomaly can be eliminated with AI in a place like Nigeria where the best candidate may not get the job, but the candidate with the "long legs and connections." Also, with the ability of AIs to make predictions based on relevant data gathered, there will be every tendency to avoid errors that would have caused companies and organisations fortune to resolve.

Nigeria too is not lagging behind when it comes to AI, the United Bank for Africa (UBA), in a bid to improve financial services with the aid of AI, unveiled the first AI Chatbot in Africa. Adewale (2019) reports that the Chatbot named Leo, is a financial assistant developed with best on class AI technology that has natural language, multi-lingual processing, machine-learning and available on two most popular social media channels. According to Adewale (2019), some of the statistics on Leo are: operating within an average time of five minutes; useful to people within the ages of 18 to 24; had one million subscribers within one year of its existence; and had 70 million conversations on the platform. Also, Ayoola (2019) reports about a Nigerian professional teacher who invented a machine that cleans chalkboards after use. The teacher, Samuel Adesola, reveals that the robot cleans and darkens chalkboards. It is a breath of fresh air that some sectors in Nigeria use AIs. It will be of tremendous advantage to the socio-economic development of the country if more individuals, government, and corporate organisations also buy into the idea of using AIs in their activities.

The mass media are not spared in the onslaught of AI on professions. Phillips (2018) reports about the AI that is being used by different organisations' to analyse more than a thousand news sources on various topics on regular basis, to gather all the details. The AI then writes an impartial version of the story, taking into consideration the trustworthiness of each news source and expunging any likely bias. It also gives unbiased headlines. In the same way, Schmelzer (2018) states that BBC News has a product for their BBC News Labs division called "Juicer". This is an AI-enhanced meta search engine that stores information about organisations, people, locations and other items of interest which can eventually be retrieved quickly for use. This is after Juicer has followed hundreds of news sources, aggregates information and extract the information on these topics when they are needed by journalists to write their stories. Similarly, the Guardian has introduced a chatbot that interacts with its readers, and this enables greater engagement with news content. These chatbots have the ability to provide additional content or context that is not available in a story or provide deeper interaction with relevant topics. As a matter of urgency, Nigerian media houses must 
commence the training of their staff, and the usage of AI in their practice. This is essential because the public look on to them to be educated about AI.

From the fore goings, it is so clear that automation (AI) may own the future, and we are still in the early stages of the AI revolution. AI has profound implications for the relationship between organisations' and their workforce worldwide.

\section{Impact of AI on the society}

The eventual utilisation of AI in most of human endeavours will surely impact the society in various way. One significant aspect to be touched is that of jobs and employment. The issue of job loss is very important while discussing AI and automation because it can to lead to mass unemployment. This is much so as numerous AI are taking over global production, and displacing skilled workers. Raju (2017) quotes the World Economic Forum`s 2016 report as saying that there will be about five million jobs lost to automation (robots and computers) by 2020. This cuts across different industries, skill, and wage levels. Lee, Larsen, Webb and Cuéllar (2019) emphasise that, as AI becomes more widespread and its performance improves, it will likely have significant long-term consequences for jobs, inequality, organizations, and competition. Elon Musk, the CEO of SpaceX and Tesla is reported by CNBC (in Omotayo, 2018) to have said that technology will take so much jobs from people that many will have to rely on a universal basic income to survive. Elon Musk suggests that AI is "a fundamental risk to the existence of civilization" (Rooney, 2019, p.2). With AI, countries like Jamaica with lower gross domestic product (GDP) per capita and greater inequality were shown to be at a greater risk of suffering job losses (Hendricks , 2018). At present, the unemployment rate in Nigeria is very high; if peradventure AI takes over most of the duties being performed by human beings, the result will be very devastating. There is the need for the government to start to plan ahead of how to manage the situation when AIs are eventually introduced in almost all the sectors in Nigeria.

Peoples` privacy are also being invaded; already Facebook is spying on users with AI without Facebook users realising it. The social network is able to recognise patterns in how you interact with things and deliver content in response (Ripples, 2016). Equally, Hughes (2017) highlights the dangers inherent in AI; this includes the hacking of the Adversarial AI whereby inputs can be carefully crafted to trick AI systems into misclassifying data. For instance, this can make an AI vision system that recognises a red traffic light, perceive a green one instead. This act can easily cause numerous automobile accidents. The hacking of AI is made simple because cyber criminals can easily lay their hands on AI tools as open software like OpenAI and Onyx. The invasion of people`s privacy has legal implications, therefore legal frameworks must be put in place before AIs can be fully deployed. Also, security agencies should be proactive in their duties so as to be able to tackle those who may want to exploit AI to commit criminal acts.

However, there are some things AI will not be able to do, like human interaction, this must be the reason Mark Cuba, the multi-companies investor who made his money investing in tech companies, must have said that the liberal arts is the way. He said he would study philosophy as his major over accounting if he were to start college all over again. Cuba based his judgment on the simple logic that AI will only be able to replace jobs that require technical skill but not those that heavily rely on personal judgement (Omotayo, 2018). In a place like Nigeria where the full deployment of AI may take some years, it is advisable that the educational sector should concentrate on teaching those things AIs can never do, because on their own AIs cannot be creative. 


\section{RESEARCH METHOD}

Content analysis method was adopted in this study. Through purposive sampling technique, The Punch, The Guardian and Vanguard newspapers were selected because of their high circulation rates and reach. They are also rich in sharp analysis and commentaries. The newspapers` editions from January to December 2019 formed the population, bringing the total to 1,095 .

A sample size of 285 was used in this study as derived through the use of the Creative Research System Calculator (1982) at 95\% level of acceptance (confidence level) and 5\% confidence interval (margin of error). A total of 285 editions of the three newspapers were studied; that is, 95 edition of each of the selected newspapers. The months and dates of the newspapers that had stories on Artificial Intelligence in 2019 were purposively searched for, identified, and selected for analysis.

The Unit of analysis for this study are the news stories, feature and opinion articles, photographs and editorials as reported by the selected newspapers. The Content categories were: Volume of coverage; it refers to the rate at which the story of AI was reported over the study period. Story Placement/Prominence; it refers to how AI stories were placed in the newspapers. They could be on the front page, inside pages, or the back page. Story type: This refers to the format, pattern, or genre of the stories; that is, they could be in form of Straight news, Editorials, Opinion Articles, Feature Articles, or photographs.

The data gathering instruments were the coding sheet and the coding guide. They were subjected to face and construct validity. Ole Holsti's (1969) formula for inter-coder reliability based on the ratio of coding agreement to the number of coding decision, as recommended by Wimmer and Dominick (2000), was used to test the instruments. They were deemed reliable with 0.96 coefficient result, representing $96 \%$ agreement between two independent coders.

\section{DATA PRESENTATION AND ANALYSIS}

Pie- Charts, degrees, and simple percentages were used to analyse data.

Fig 1. Pie Chart showing frequency of AI stories in the selected newspapers in 2019.

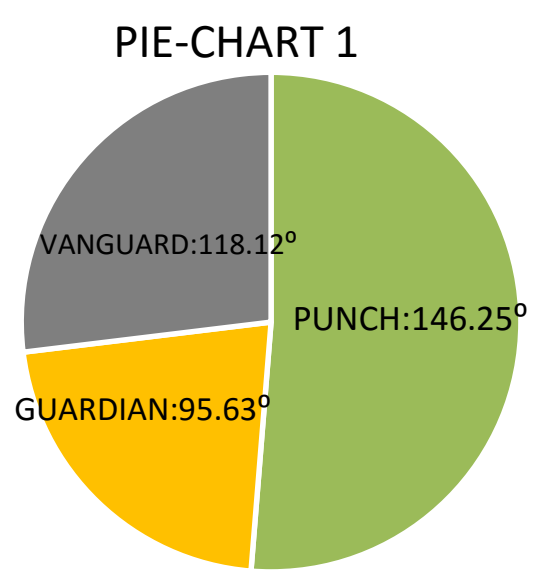

KEY: Punch: Guardian: Vanguard: Scale: $1 \%=3.6^{0}$ 
Fig 1 shows that only 64 stories about Artificial Intelligence were reported in the whole of 2019 by the selected newspapers. The Punch had $26\left(146.25^{\circ}\right)$, that is, $40.62 \%$ stories, The Guardian had 17 $\left(95.63^{\circ}\right)$, that is, $26.56 \%$ stories, and Vanguard had $21\left(118.12^{\circ}\right)$, that is, $32.81 \%$ stories. The reportage is abysmally small. It does not align with the AI trend that is going on in the world, and will eventually result to shutting Nigeria out of the global market in the nearest future.

Fig 2. The story types with which AI stories were presented by the selected newspapers in 2019.

\section{PIE-CHART 2}

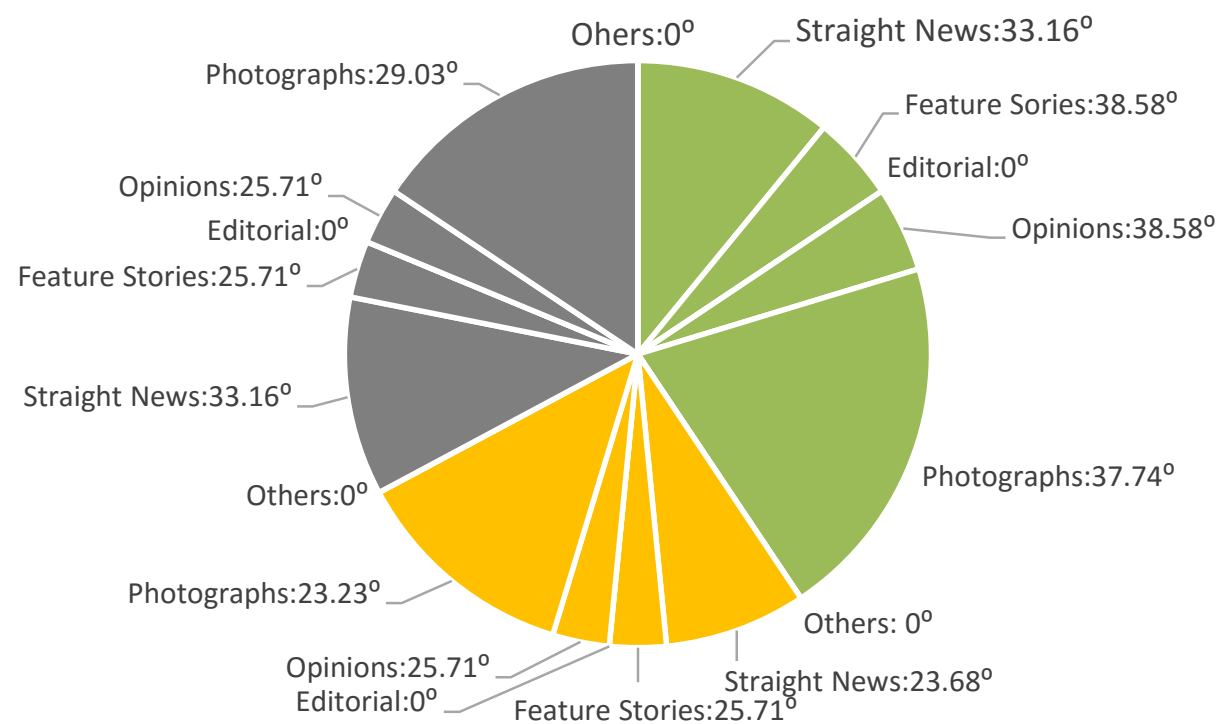

KEY: Punch: Guardian: Vanguard: Scale: $1 \%=3.6^{0}$

The data on Fig 2 contain information about the number of times a sub-category appeared in the newspapers. The chart shows the format, pattern or story type with which the stories were reported, that is, through Straight news, editorial, feature articles, opinion articles, photographs, or others. The data show that the newspapers had more photographs $31\left(174.38^{\circ}\right)$, that is, $48.45 \%$ in presenting their AI stories more than any other story type in the newspapers for the period under review. This is followed by Straight news with $19\left(106.88^{\circ}\right)$, that is, $29.69 \%$, and feature stories and opinion articles that had $7\left(39.37^{\circ}\right)$, that is, $10.93 \%$ each. 
Fig 3. Prominence of Editorial Items

\section{PIE-CHART 3}

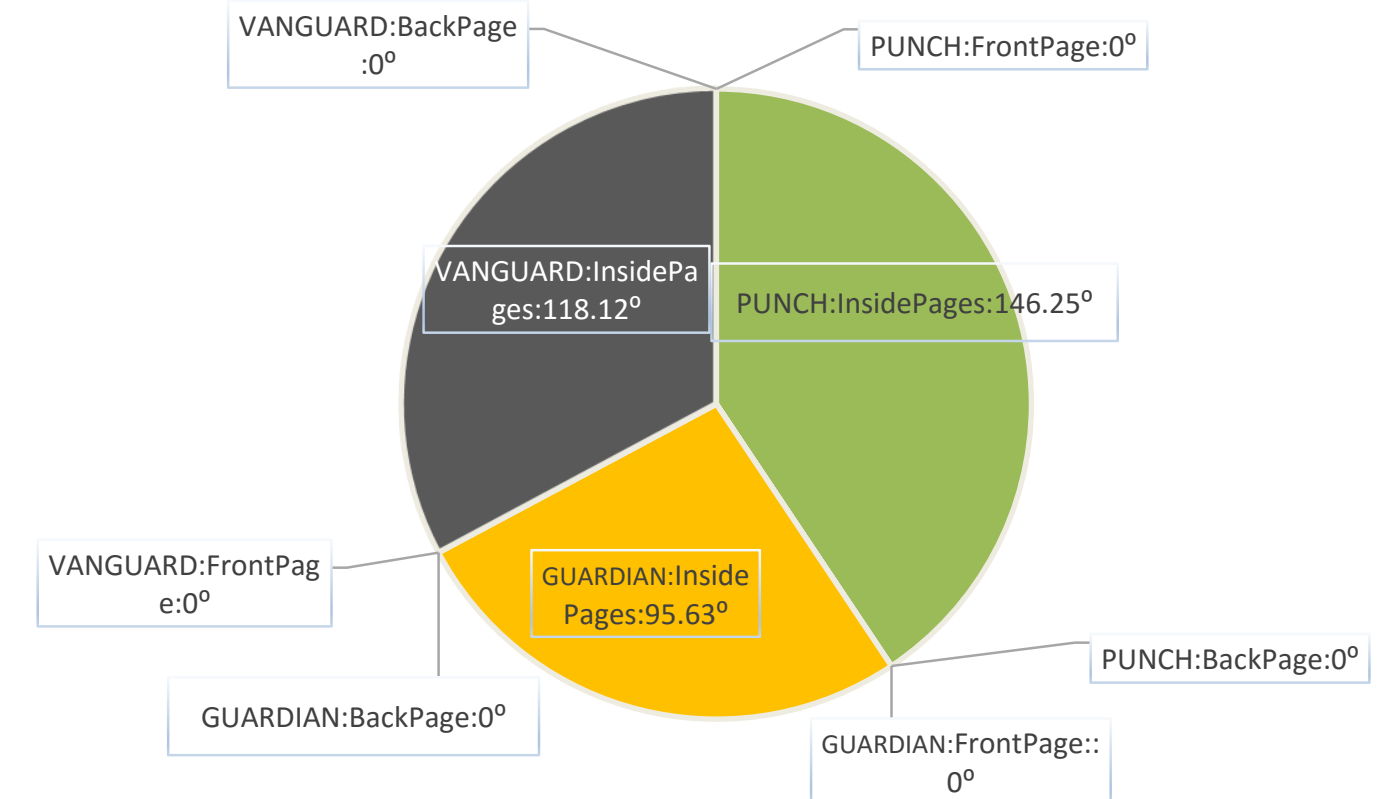

KEY: Punch: Guardian: Vanguard: Scale: $1 \%=3.6^{0}$

Pie Chart 3 shows that all the stories and reports relating to AI were only in the inside pages of the selected newspapers. This portrays that prominence was not given to AI reports by the newspapers throughout the year 2019 .

\section{DISCUSSION OF FINDINGS}

The first research objective for this study was to determine the frequency with which the newspapers reported about Artificial Intelligence throughout the period of study which was from January to December, 2019. This first finding shows that only a minimal 64 reports were made. This low figure indicts the newspapers for not performing their cut-out role of creating awareness. It is insufficient to raise the awareness about AI. The finding contradicts the position of Lasswell (1976) who opines that the media have the responsibility of informing the citizens on issues of national interest. This under reporting about AI can make the people ignorant, and be unable to cope and compete with the rest of the world in all the areas that AI will be deployed. Hence, Ndiomewese (2017) affirms the ignorance of the average Nigerian that AI powers most things from their email, music playlists to social media feeds. There is the need for newspapers to start to report the reality, scope and disruptive imports of AI to Nigeria and Nigerians. Newspaper reporters need to deepen their reporting by digging into knowing more about AI so that they can easily interpret how they function to the understanding of the public.

This finding also reveals that Nigerian newspapers hardly give adequate reports about issues as important as AI, but rather give more attention to political stories as attested to by the outcomes of earlier researches carried out by scholars like Weber (1990), Oso and Odunlami (2008) and Gupta and Sinha (2010). Their findings corroborate the first finding of this present study, that the mass media in Nigeria often give more coverage to political issues than other pressing issues of national interest. As agenda setters, one would have expected the newspapers 
to give adequate volume of coverage to AI reports, since the amount of times an issue is reported could be responsible for setting agenda (Anaeto, Onabajo \& Osifeso, 2012), but that was not the case. Hence it can be claimed that the newspapers failed to set agenda on AI for the whole of 2019.

The second finding indicates that no prominence was given to AI reports. This means that $\mathrm{AI}$ is yet to be given its rightful placement in the Nigerian newspapers 'landscape. It shows the newspapers do not give priority to the danger that looms in the future in a non-AI compliant society that is bound to be left behind in the scheme of things. This finding does not correlate with the functions of newspapers which Illah, Ogwo and Asemah (2012) say "have the capabilities to manipulate vision and get the people constantly fixed to issues that are given prominence in their agenda. The issues they give prominence, are those issues we worry about" (p.14). That prominence was not also given to the AI reports underscores the fact that the newspapers did not attach importance to AI stories. It negates the principles of the Agenda Setting Theory that would have given the readers "what to think about." Newspapers need to refocus their story-placement policies so that salient issues like that of AI can regularly appear in vantage positions of newspapers like the front and back pages. With this, readers' attention can be easily drawn to read such stories.

Already experts have said it will take Nigeria a minimum of eleven years to level up on AI globally (Olanrewaju. 2018; Ndiomewese, 2017). If newspapers do not start to give prominence to AI issues now, it may take more than eleven years for Nigeria to catch up. The fact that Journalists might not be reporting about AI intensely now may be attributed to the fact that they lack in-depth knowledge about AI and its imports on the society, and even on journalism profession.

The third finding reveals that all the stories about AI were basically in form of photographs accompanying the news stories about AI. Photographs are very effective in information provision and transmission as argued by Kujenye and Agbro (2008) who say a picture (photograph) tells stories of a million words. The photograph is a powerful tool of communication that can be used to effectively send out messages because of its aesthetic values. However, the usage of more feature and opinion articles would have served better because the feature article is an in-depth and factual write up on topical issues which seeks to give comprehensive information in a more captivating and relaxed style than straight news (Okoye, 2006). According to Guanah (2014), feature can be used to "meat up" the bones of the straight news. With series of story types like opinion articles, features, and interview with experts in the field of new media technologies, computer and automation being used, newspapers will have ample opportunity to give details about AI. This will avail readers the opportunity to learn more about it, and therefore start to utilise them in the different areas they are useful to them now.

Also, newspapers can effectively use their editorials to drive home points about AI since an editorial states the stand of a newspaper concerning any particular issue that is of public importance and advantage. Though an editorial is the opinion of the management of a media outfit, and reflects a Newspaper's view on an issue, event or a subject matter, yet, through it, a newspaper can influence a person or group of persons to take action, or support a particular view that the newspaper believes is right, especially when it concerns readers' lives and wellbeing. Really, a newspaper can bring about significant changes in any environment it is domiciled, and the people it can reach, through its vigorous editorials and news reportage. It is necessary that newspapers report about AI intensely now because with AI, "The future is already here" (Abdullah, 2018, p.2). 


\section{CONCLUSION}

Based on the findings of this study, it can be concluded that the selected newspapers did not give considerable report to AI issue. Though the newspapers featured few stories about AI, however, they were mostly presented in the form of photographs and Straight news. All genres of story type ought to be used to present robust information about AI and its operations through the newspapers. This is very important because it is the duty of newspapers to "break down news to let the audience make sense of them by analysing knotty issues for the public to understand, and its permanent nature is of great advantage to it" (Guanah \& Obi, 2019, p.13). Since automation may be the future, newspapers must start to intensify the education of the public about AI through their coverage.

\section{Recommendations}

i. Newspapers should commence full reportage about AI to draw attention to its effects in the nearest future, so that all stakeholders can start to make preparations to cope with it.

ii. Prominence must be given to AI stories for easy attention and reading by all because front page stories are important and can easily catch readers`attention.

iii. Newspapers should carry out in-depth investigations and analysis of the modus operandi of AI, inform of feature and opinion articles so that readers can have a better understanding of AI.

iv. Also, newspapers should report AI stories with all story types, and place such stories in all the prime sections of the newspapers.

\section{REFERENCES}

Abdullah, N. H. (2018). Future-focus-ingenuity-sustaining-our-future. Retrieved from https://www.facebook.com/DGHisham/posts/2144108348946375.

ACE Project (20190. The ACE Encyclopaedia: Media and Elections. 2009. Retrieved from http://aceproject.org/ace-en/topics/me/default/mobile browsing/onePag.

Adewale, B. (2019). Social Media Week: UBA unveils AI Chatbot to improve financial services. Retrieved from https://www.today.ng/technology/social- media- week- uba- unveilschatbot-improve-financial-services-192785.

Afolayan, K. (2020). Nigeria Made \$104 Million From Film And Music In 2019- Lai Mohammed. Retrieved from https://www.naijaloaded.com.ng/news/nigeria-made-104million-from-film-and-music-in-2019-lai-mohammed.

Anaeto, S. G., Onabajo, O. S. \& Osifeso, J. B. (2012). Models and theories of communication. Maryland: African Renaissance Books Incorporated.

Ayoola, S. (2019). Nigerian man creates robot for cleaning and darkening boards. Retrieved from https://www.legit.ng/1228770-nigerian-man-creates-robot-cleaning-darkeningboards.htmlgit.ng.

Azeez, L. A. (2009). The role of the media in reporting terrorism: A personal viewpoint. Journal of Communication and Media Research, 1(1): 11-16.

Baran, S. J. \& Davis, D. K. (1995). Mass Communication: Theory, Foundations, Ferment and Future. Belmont, California: Wadsworth Publishing Company. 
Cann, O. (2018). These are the top 10 emerging technologies of 2018. Retrieved from https://www.weforum.org/agenda/2018/09/top- 10-emergingtechnologies-of-2018/.

Cohen, B. (1963). The Press, the public and foreign policy. Princeton, NJ: Princeton University Press.

Creative Research Systems Calculator (1982). Sample Size Fomulas for our sample size calculator. Assessed at https://www.surveysystem.com/sscalc.htm.

Daramola, I. (2001). Introduction to mass communication. Lagos: Rothan Press.

Ferro, S. (2018). The Next Job Being Taken Over by Robots? TV News Anchor. Retrieved from http://mentalfloss.com/article/527709/next-job-being-taken-over-robots-tv-news-anchor.

Giardina, C. (2017). How Artificial Intelligence Will Make Digital Humans Hollywood's New Stars. Retrieved from http://www.hollywoodreporter.com/behindscree n/how-artificial-intelligence-will-make-digital-humans-hollywoods-new-stars-1031553.

Griffin, E. (2003). A First look at Communication Theory. New York: McGraw Hill ITU International Telecommunications.

Guanah, S. J. \& Obi, I. (2019). Media and the Restructuring Discourse: Newspapers` reports the morning after Nigeria`s 2019 General elections. Paper presented at the 32nd Annual Convention and International Conference of the Society of Nigeria Theatre Artists (SONTA), held atNiger Delta University, Wilberforce Island, Bayelsa State, Nigeria, from 31st October -3rd November, 2019.

Guanah, S. J. (2014). Comparative study of Nigerian press coverage of male and female aspirants in the 2013 gubernatorial election in Anambra State. Unpublished M.Sc. Dissertation, Faculty of Social Science. Igbariam: Anambra State University.

Gupta, A. \& Sinha, A. K. (2010). Health coverage in Mass Media: A Content Analysis. Journal of Communication, 1(1):19-25.

Hall, S. (2018). Can you tell if this was written by a robot? 7 challenges for AI in journalism. Retrieved from https://www.weforum.org/agenda/2018/01/can-you-tell-if-thisarticle was-written-by-a-robot-7-challenges-for-ai-in-journalism/.

Handley, L. (2018). Experts cast doubt on whether China's news anchor is really A.I. Retrieved from https://www.cnbc.com/2018/11/16/experts-cast-doubt-on-whetherchinas-news-anchor-is-really-ai.html.

Hendricks, S. (2018). 2019 and beyond...what to expect from artificial intelligence. Retrieved from http://www.jamaicaobserver.com/news/2019-and-beyond-what-to-expect-fromartificial-intelligence 153343 ? profile=1373.

Houser, K. (2019). This robot could be conducting your next job interview. Retrieved from https://www.weforum.org/agenda/2019/03/see-the-robot-head-that-mightinterview-you-for-your-next-job.

Hughes, M. (2017). Artificial intelligence is now an arms race. What if the bad guys win? Retrieved from https://www.weforum.org/agenda/2017/11/cybersecurity-artificialintelligence-arms-race/. 
Illah, J.; Ogwo, C. O. \& Asemah, E. (2012). Nigerian newspapers and sensational journalism practice: A content analysis of four newspapers. Benin Mediacom Journal, No. 6: 12-22.

Kuziemski, M. (2017). It's make or break time for artificial intelligence: Here's how we can make it work. Retrieved from https://www.weforum.org/agenda/2017/05/artificial-intelligencewill-make-or-break-us-heres-how-we-need-to-respond.

Kujenye, J. \& Agbro, J. (2008, October 26). The world of humour merchants. The Nation, Pp. 17, $18 \& 19$.

Lasswell, H. D. (1976). The policy sciences of development in world politics, 17(2):286-309.

Lee, S. Y., Larsen, C. B., Webb, M. \& Cuéllar. M. F. (2019). AI regulation and firm behavior. Retrieved from https://voxeu.org/article/ai- regulation- and- firmbehaviour?\&utm source=sfmc\&utm medium=email\&utm campaign=2708437 Agenda weekly-FinalTemplate-20December2019-20191218 064732\&utm term=\&emailType=.

Leprince-Ringuet, D.(2019). Artificial Intelligence. Retrieved from https://www.zdnet.com/articl e/this-new-ai-tool-can-spot-if-you-are-nervous-or-confused/.

Marciano, J. (2017). 20 to lawyers were beaten by legal AI. Here are their surprising responses. R etrieved from https://hackernoon.com/20-top-lawyers-were-beaten-by-legal-ai-here-aretheir-surprising-responses-5dafdf25554d.

McCombs, M. E. \& Shaw, D. L. (1972). The agenda-setting function of mass media, Public Opinion Quarterly, 36 (2): 176-187, University of Derby. Retrieved from http: poq.oxfordjournals.org/content/36/2/176.

Ndiomewese, I. (2017). Experts answer 9 questions on the state of Artificial Intelligence in Nigeria. Retrieved from https://techpoint.africa/2017/09/26/artificialintelligence-nigeria/.

Nwabueze, C. (2019a). VaakEye! Artificial intelligence software that can catch shoplifters even b efore they steal (Video). Retrieved from https://massmediang.com/vaakeye-artificialintelligence-software-that-can-catch-shoplifters-even-before-they-steal-video/.

Nwabueze, C. (2019b). Expert Considers 'Google BRAIN' chip which could mean future school pupils won`t need to memorise facts. Retrieved from https://massmediang.com/expertconsiders-google-brain-chip-which-could-mean-future-school-pupils-wont-need-tomemorise-facts/.

Nwabueze, C. D. (2018). Top 10 National Dailies in Nigeria. Retrieved from https://massmedian g.com/newspapers-top-10-national-dailies-in-nigeria/.

Okoye, I. (2006). Feature writing: Theory and practice. Lagos: Malthouse Press Limited.

Olanrewaju. B. (2018).Artificial intelligence and Nigeria dearth system. Retrieved from http://nig eriannewsdirect.com/96246-2/.

Omotayo, J. (2018). Bill Gates, Jack Ma, 2 others advise students on what to study for highpaying jobs. Retrieved from https://www.legit.ng/1239382-bill-gates-jack-ma-2-advisestudents-study-high-paying-jobs.html.ng.

Onayiga, G. (2016). The Nigerian Media and the Re-Shaping of the National Economy. Being a keynote address at the NRGI-Nigeria`s Media for Oil Reform (MFOR) Conference held at the Lagos Business School, Pan-Atlantic University, Lagos on Wednesday, April 13. 
Oso, L. \& Odunlami, D. (2008). Breadth or Depth: A Content Analysis of Health Pages in the Nigerian Press. Social Health Matters, 9(1): 9-13.

Phillips, M. (2018). How artificial intelligence will be used for news media in 2019. Retrieved from https://www.twipemobile.com/how-artificial-intelligence-used-news-media-2019/.

Raju, A. (2017). Virtual realities. Retrieved from http://www.thehindu.com/todays-paper/tpfeatures/tp-educationplus/virtual-realities/article17534250.

Ripples (2016). Facebook spying on users with Artificial Intelligence. Retrieved from www.ripple s.com.ng/facebook- spying- on- users- with- artificial- intelligence/.

Rooney, K. (2019). Two-thirds of employees would trust a robot boss more than a real one. Retrieved from https://www.weforum.org/agenda/2019/11/robot- boss- artificialintelligence-jobs/?utm source=sfmc\&utm medium=email\&utm campaign=2706682 Age nda weekly-22November2019-20191120 082301\&utm term=\&emailType $=$.

Schlesinger, P., Murdock, G. \& Elliot, P. (1983). Televising Terrorism: Political Violence in Popular Culture. London: Comedia Publishing Company.

Schmelzer, R. (2018). Automated journalism creeps into newsrooms leaning on AI. Retrieved from https://searchenterpriseai.techtarget.com/feature/Automated-journalism-creeps-intonewsrooms-leaning-on-AI.

Sherman, J. A. (2018). Now is the time to figure out the ethical rights of robots in the workplace. Retrieved from https://www.cnbc.com/2018/12/27/now-is-the-time-to-figure-out-theethical-rights-of-robots-in-the-workplace-.html.

Thornton, A. (2019). How AI and satellites are used to combat illegal fishing. Retrieved from https://news.microsoft.com/on- the- issues/2019/06/06/ocean- mind- illegalfishing/?ocid=FY19 soc omc cela tw OceanMind5 2.

Umeh, J. (2019). 4th Industrial Revolution: Artificial Intelligence, IoT, Blockchain lead the way. Retrieved from https://www.vanguardngr.com/2019/04/4th- industrial- revolutionartificial-intelligence-iot-blockchain-lead-the-way/.

Vinuesa, R., Azizpour, H. \& Nerini, F. F. (2020). The role of artificial intelligence in achieving the Sustainable Development Goals. Nature Communications, Volume 11, Article number: 233. Retrieved from https://www.nature.com/articles/s41467-019-14108-y.

Walgrave, S., Soroka, S. \& Nuytemans, M. (2008). The Mass Media's Political Agenda-Setting Power: A Longitudinal Analysis of Media, Parliament, and Government in Belgium (1993 to 2000)", Comparative Political Studies, 41:

814. Retrieved from http://www.m2p.be/index.php?page=publications\&id=56.

Walgrave, S. \& Aelst, V. P. (2006). The Contingency of the Mass Media's Political Agenda Setting Power: Toward a Preliminary Theory. Journal of Communication, 56:92. R etrieved from http://www.m2p.be/publications/00101132.pdf.

Weber, R. P. (1990). Basic content Analysis (2nd ed). Beverly Hills: CA: Sage Publications.

White, E. \& Pinsky, O. (2018). Half the world's population is still offline, here is why that matters. Retrieved from https://www.weforum.org/agenda/2018/05/half-theworld-s-population-is-still-offline-heres-why-that-matters/. 
Wimmer, R. D. \& Dominick, J. R. (2000). Mass media research: An introduction (6th ed.). Belmont-California: Wadsworth Publishing Company.

Wright, C. R. (1986). Mass Communication (3rd Ed), New York: Random House.

Xiang, N. (2019). 10 expert predictions for the next decade in Chinese AI. Retrieved from https://www.weforum.org/agenda/2019/07/what- experts- predict- for- the- nextdecade-in-chinese-ai/. 